\title{
Fixed point theorems for C-class functions in b-metric spaces and applications
}

\author{
Huaping Huang ${ }^{a}$, Guantie Deng ${ }^{a, *}$, Stojan Radenovićb \\ a School of Mathematical Sciences, Beijing Normal University, Laboratory of Mathematics and Complex Systems, Ministry of Education, \\ Beijing, 100875, China. \\ ${ }^{b}$ Faculty of Mechanical Engineering, University of Belgrade, Kraljice Marije 16, 11120, Beograd, Serbia.
}

Communicated by W. Shatanawi

\begin{abstract}
The aim of this paper is to present some fixed point results for C-class functions in the setting of b-metric spaces. Moreover, some examples are given to support the main results. In addition, by using our results, we obtain the existence and uniqueness of solution to differential or integral equation. Furthermore, for the differential equation, we provide the precise mathematical expression of solution. (c) 2017 All rights reserved.
\end{abstract}

Keywords: C-class function, b-metric space, fixed point, altering distance function, integral equation. 2010 MSC: $47 \mathrm{H} 10,54 \mathrm{H} 25$.

\section{Introduction}

In the development of nonlinear analysis, fixed point theory occupies a prominent place in many aspects. It has been used in different branches of engineering and sciences. In particular, the famous Banach contraction principle, is very popular tool of mathematics in solving a great deal of problems in several branches of mathematics such as variational and linear inequalities, differentio-integral equation, and approximation theory. To overcome the problem of measure and the convergence induced by measurable functions, Bakhtin [5] or Czerwik [7] introduced an extension of metric space, which is called b-metric space or metric type space, and proved a more general Banach contraction principle in such space. Since then, many authors have been interested in investigating fixed point theorems for single-valued and setvalued mappings in b-metric spaces (see [2, 6, 8, 9, 11-17, 19-23]). On the other hand, Khan et al. [10] introduced the concept of altering distance function, which is a control function that alters distance between two points in a metric space. Some mappings will become weak if they act with altering distance functions. Afterwards, many mathematicians obtained fixed point theorems associated with altering distance functions (see [13, 20-23]). Recently, Ansari [3] introduced C-class function in metric spaces and

\footnotetext{
*Corresponding author

Email addresses: mathhhp@163.com (Huaping Huang), denggt@mail .bnu.edu.cn (Guantie Deng), radens@beotel.net (Stojan Radenović)
}

doi:10.22436/jnsa.010.11.23 
obtained some fixed point results. Subsequently, many scholars were interested in fixed point theorems for C-class function (see $[4,13,18]$ ). Throughout this paper, inspired and motivated by previous results in the existing literature, we give several fixed point results for C-class functions in b-metric spaces. Our results are straightforward and our proofs avoid the problem of discontinuity of b-metric. Yet, in some previous results, the authors had to utilize the so-called famous lemma because of the problem of discontinuity of b-metric. Moreover, we provide two examples to support our main assertions. Otherwise, we apply our results to prove the existence and uniqueness of a solution to ordinary differential equation with initial value conditions. Further, we give the concrete mathematical expression of solution to such equation. In addition, we deal with the existence and uniqueness of a solution to a class of nonlinear integral equations.

In the sequel, we always denote by $\mathbb{N}, \mathbb{R}$, and $\mathbb{R}^{+}$the set of positive integers, real numbers, and nonnegative real numbers, respectively. The following definitions and results will be useful for proving our main results.

Definition 1.1 ([5,7]). Let $X$ be a (nonempty) set and $s \geqslant 1$ be a given real number. A function $d: X \times X \rightarrow$ $\mathbb{R}^{+}$is called a b-metric on $X$ if, for all $x, y, z \in X$, the following conditions hold:

(b1) $d(x, y)=0$ if and only if $x=y$;

(b2) $d(x, y)=d(y, x)$;

(b3) $d(x, z) \leqslant s[d(x, y)+d(y, z)]$.

In this case, the pair $(X, d)$ is called a $b$-metric space.

It is evident that the class of $b$-metric space is larger than that of metric space since any metric space is a $b$-metric space with $s=1$. The following examples show that, in general, a b-metric space is not necessarily a metric space.

Example 1.2 ([14, 20,21]). Let $(X, d)$ be a metric space and $\sigma_{d}: X \times X \rightarrow \mathbb{R}^{+}$be defined by

$$
\sigma_{d}(x, y)=[d(x, y)]^{p} \text { for all } x, y \in X,
$$

where $p>1$ is a fixed real number. Then $\left(X, \sigma_{d}\right)$ is a b-metric space with coefficient $s=2^{p-1}$.

In the following examples, we improve the coefficient of $b$-metric space in several papers (see $[6,11,20-$ 23]). As a matter of fact, we replace the coefficient $s=2^{\frac{1}{p}}$ by $s=2^{\frac{1}{p}-1}$.

Example 1.3. Let $0<p<1$ and define $L_{p}[a, b]$ by

$$
\mathrm{L}_{p}[\mathrm{a}, \mathrm{b}]:=\left\{\left.x(\mathrm{t})\left|\int_{a}^{b}\right| x(t)\right|^{p} d t<\infty\right\}
$$

where the mapping $d: L_{p}[a, b] \times L_{p}[a, b] \rightarrow \mathbb{R}^{+}$is defined by

$$
d(x, y)=\left(\int_{a}^{b}|x(t)-y(t)|^{p} d t\right)^{\frac{1}{p}}
$$

for each $x=x(t), y=y(t) \in L_{p}[a, b]$. Then $\left(L_{p}[a, b], d\right)$ is a b-metric space with coefficient $s=2^{\frac{1}{p}-1}$.

In fact, we only need to prove that condition (b3) in Definition 1.1 holds. To this end, let $x=x(t)$, $y=y(t), z=z(t)$, we show that

$$
\left(\int_{a}^{b}|x(t)-z(t)|^{p} d t\right)^{\frac{1}{p}} \leqslant 2^{\frac{1}{p}-1}\left[\left(\int_{a}^{b}|x(t)-y(t)|^{p} d t\right)^{\frac{1}{p}}+\left(\int_{a}^{b}|y(t)-z(t)|^{p} d t\right)^{\frac{1}{p}}\right] .
$$


Denote $u(t)=x(t)-y(t), v(t)=y(t)-z(t)$, then $x(t)-z(t)=u(t)+v(t)$, so (1.1) becomes

$$
\left(\int_{a}^{b}|u(t)+v(t)|^{p} d t\right)^{\frac{1}{p}} \leqslant 2^{\frac{1}{p}-1}\left[\left(\int_{a}^{b}|u(t)|^{p} d t\right)^{\frac{1}{p}}+\left(\int_{a}^{b}|v(t)|^{p} d t\right)^{\frac{1}{p}}\right] .
$$

Next we prove (1.2). Noticing the following inequalities,

$$
\begin{aligned}
& (a+b)^{p} \leqslant a^{p}+b^{p} \quad(a, b \geqslant 0,0<p \leqslant 1), \\
& (a+b)^{p} \leqslant 2^{p-1}\left(a^{p}+b^{p}\right) \quad(a, b \geqslant 0, p \geqslant 1),
\end{aligned}
$$

we have

$$
\begin{aligned}
\left(\int_{a}^{b}|u(t)+v(t)|^{p} d t\right)^{\frac{1}{p}} & \leqslant\left(\int_{a}^{b}(|u(t)|+|v(t)|)^{p} d t\right)^{\frac{1}{p}} \\
& \leqslant\left(\int_{a}^{b}\left(|u(t)|^{p}+|v(t)|^{p}\right) d t\right)^{\frac{1}{p}} \\
& =\left(\int_{a}^{b}|u(t)|^{p} d t+\int_{a}^{b}|v(t)|^{p} d t\right)^{\frac{1}{p}} \\
& \leqslant 2^{\frac{1}{p}-1}\left[\left(\int_{a}^{b}|u(t)|^{p} d t\right)^{\frac{1}{p}}+\left(\int_{a}^{b}|v(t)|^{p} d t\right)^{\frac{1}{p}}\right] .
\end{aligned}
$$

Similar to Example 1.3, we can easily get the following example.

Example 1.4. Let $0<p<1$ and define $l_{p}(\mathbb{R})$ by

$$
\mathrm{l}_{\mathfrak{p}}(\mathbb{R}):=\left\{\left.\left\{x_{n}\right\} \subseteq \mathbb{R}\left|\sum_{n=1}^{\infty}\right| x_{n}\right|^{p}<\infty\right\},
$$

where the mapping $d: l_{\mathfrak{p}}(\mathbb{R}) \times l_{\mathfrak{p}}(\mathbb{R}) \rightarrow \mathbb{R}^{+}$is defined by

$$
d(x, y)=\left(\sum_{n=1}^{\infty}\left|x_{n}-y_{n}\right|^{p}\right)^{\frac{1}{p}}
$$

for each $x=\left\{x_{n}\right\}, y=\left\{y_{n}\right\} \in l_{p}(\mathbb{R})$. Then $\left(l_{p}(\mathbb{R}), d\right)$ is a $b$-metric space with coefficient $s=2^{\frac{1}{p}-1}$.

Example 1.5 ([20]). Let $X=\{0,1,2\}$ and define the mapping $d: X \times X \rightarrow \mathbb{R}^{+}$by

$$
\mathrm{d}(0,0)=\mathrm{d}(1,1)=\mathrm{d}(2,2)=0, \quad \mathrm{~d}(0,1)=\mathrm{d}(1,0)=\mathrm{d}(1,2)=\mathrm{d}(2,1)=1
$$

and

$$
\mathrm{d}(2,0)=\mathrm{d}(0,2)=\mathrm{m},
$$

where $m \geqslant 2$ is a real number. Then $(X, d)$ is a b-metric space with coefficient $s=\frac{m}{2}$.

Definition $1.6([20,21])$. Let $(X, d)$ be a b-metric space and $\left\{x_{n}\right\}$ a sequence in $X$. We say that

(1) $\left\{x_{n}\right\}$ b-converges to $x \in X$ if $d\left(x_{n}, x\right) \rightarrow 0$ as $n \rightarrow \infty$;

(2) $\left\{x_{n}\right\}$ is a b-Cauchy sequence if $d\left(x_{m}, x_{n}\right) \rightarrow 0$ as $m, n \rightarrow \infty$; 
(3) $(X, d)$ is b-complete if every b-Cauchy sequence in $X$ is b-convergent.

Each $b$-convergent sequence in a b-metric space has a unique limit and it is also a b-Cauchy sequence. Moreover, in general, a b-metric is not necessarily continuous. The following example illustrates this claim.

Example 1.7 ([8]). Let $X=\mathbb{N} \cup\{\infty\}$. Define a mapping $d: X \times X \rightarrow \mathbb{R}^{+}$as follows:

$$
d(m, n)= \begin{cases}0, & \text { if } m=n, \\ \left|\frac{1}{m}-\frac{1}{n}\right|, & \text { if one of } m, n(m \neq n) \text { is even and the other is even or } \infty, \\ 5, & \text { if one of } m, n(m \neq n) \text { is odd and the other is odd or } \infty, \\ 2, & \text { others. }\end{cases}
$$

It is not hard to verify that

$$
d(m, p) \leqslant \frac{5}{2}[d(m, n)+d(n, p)] \quad(m, n, p \in X) .
$$

Then $(X, d)$ is a b-metric space with coefficient $s=\frac{5}{2}$. Choose $x_{n}=2 n(n \in \mathbb{N})$, then

$$
d\left(x_{n}, \infty\right)=\frac{1}{2 n} \rightarrow 0 \quad(n \rightarrow \infty)
$$

that is, $x_{n} \rightarrow \infty(n \rightarrow \infty)$. However, $d\left(x_{n}, 1\right)=2 \nrightarrow 5=d(\infty, 1)(n \rightarrow \infty)$.

Definition 1.8 ([3]). A mapping $\mathrm{F}: \mathbb{R}^{+} \times \mathbb{R}^{+} \rightarrow \mathbb{R}$ is called a C-class function if

(i) $F(s, t) \leqslant s$ for all $s, t \geqslant 0$;

(ii) $F(s, t)=s$ implies that either $s=0$ or $t=0$ for all $s, t \geqslant 0$;

(iii) $F(s, t)$ is continuous on its variables $s, t \geqslant 0$.

Motivated by [4, Example 2.2] and [13, Example 1.10], we give the following example.

Example 1.9. Each of the following functions $F: \mathbb{R}^{+} \times \mathbb{R}^{+} \rightarrow \mathbb{R}$ is a C-class function:

(1) $F(s, t)=s-t$;

(2) $F(s, t)=\ln \frac{t+e^{s}}{1+t}$;

(3) $F(s, t)=\ln \frac{1+e^{s}}{2}$;

(4) $\mathrm{F}(\mathrm{s}, \mathrm{t})=\lambda \mathrm{s}$, where $0<\lambda<1$;

(5) $F(s, t)=\frac{s}{(1+t)^{\alpha}}$, where $\alpha>0$;

(6) $F(s, t)=(s+\beta)^{\frac{1}{(1+t)^{\alpha}}}-\beta$, where $\alpha>0, \beta>1$;

(7) $F(s, t)=s \log _{t+a} a$, where $a>1$;

(8) $F(s, t)=s \varphi(t)$, where $\varphi: \mathbb{R}^{+} \rightarrow[0,1]$ is a continuous function such that $\varphi(t)=1 \Leftrightarrow t=0$;

(9) $F(s, t)=s-\varphi(t)$, where $\varphi: \mathbb{R}^{+} \rightarrow \mathbb{R}^{+}$is a continuous function such that $\varphi(t)=0 \Leftrightarrow t=0$;

(10) $F(s, t)=\operatorname{sh}(s, t)$, where $h: \mathbb{R}^{+} \times \mathbb{R}^{+} \rightarrow \mathbb{R}^{+}$is a continuous function such that $h(s, t)<1$ for all $s, t \geqslant 0$.

In 1984, Khan et al. [10] introduced altering distance function as follows:

Definition 1.10 ([10]). A function $\varphi: \mathbb{R}^{+} \rightarrow \mathbb{R}^{+}$is called an altering distance function if it satisfies the following axioms:

(i) $\varphi$ is nondecreasing and continuous;

(ii) $\varphi(t)=0$ if and only if $t=0$. 
Example 1.11 ([20,21]). Let $\varphi_{i}: \mathbb{R}^{+} \rightarrow \mathbb{R}^{+}, i \in\{1,2, \ldots, 7\}$, be defined by

(1) $\varphi_{1}(t)=k t$, where $k>0$;

(2) $\varphi_{2}(t)=t^{\alpha}$, where $\alpha>0$;

(3) $\varphi_{3}(t)=\sinh ^{-1} t$;

(4) $\varphi_{4}(\mathrm{t})=\cosh \mathrm{t}-1$;

(5) $\varphi_{5}(t)=a^{t}-1$, where $a>0$ and $a \neq 1$;

(6) $\varphi_{6}(t)=\ln (k t+1)$, where $k>0$;

(7) $\varphi_{7}(t)= \begin{cases}\frac{t}{3}, & \text { if } t \in[0,1] \\ t-\frac{2}{3}, & \text { if } t \in(1, \infty)\end{cases}$

Then $\varphi_{i}(i=1,2, \ldots, 7)$ are altering distance functions.

For the sake of overcoming the problem of discontinuity for b-metric, the following lemma was often used by many authors (see [1, 15, 20-23]).

Lemma $1.12([1])$. Let $(X, d)$ be a b-metric space with coefficient $s \geqslant 1$ and let $\left\{x_{n}\right\}$ and $\left\{y_{n}\right\}$ be b-convergent to points $x, y \in X$, respectively. Then we have

$$
\frac{1}{s^{2}} d(x, y) \leqslant \liminf _{n \rightarrow \infty} d\left(x_{n}, y_{n}\right) \leqslant \limsup _{n \rightarrow \infty} d\left(x_{n}, y_{n}\right) \leqslant s^{2} d(x, y)
$$

In particular, if $x=y$, then we have $\lim _{n \rightarrow \infty} \mathrm{d}\left(x_{n}, y_{n}\right)=0$. Moreover, for each $z \in X$, we have

$$
\frac{1}{s} d(x, z) \leqslant \liminf _{n \rightarrow \infty} d\left(x_{n}, z\right) \leqslant \limsup _{n \rightarrow \infty} d\left(x_{n}, z\right) \leqslant s d(x, z) .
$$

\section{Main results}

Let $f: X \rightarrow X$ be a mapping. Assume that

$$
\begin{gathered}
M_{1}(x, y)=\max \left\{d(x, y), \frac{d(x, f x) d(y, f y)}{1+d(x, y)}, \frac{d(x, f x) d(y, f y)}{1+d(f x, f y)}\right\}, \\
M_{2}(x, y)=\max \left\{d(x, y), \frac{d(x, f x) d(x, f y)+d(y, f y) d(y, f x)}{1+s[d(x, f x)+d(y, f y)]},\right. \\
\left.\frac{d(x, f x) d(x, f y)+d(y, f y) d(y, f x)}{1+s[d(x, f y)+d(y, f x)]}\right\}, \\
M_{3}(x, y)=\max \left\{d(x, y), \frac{d(x, f x) d(y, f y)}{1+s[d(x, y)+d(x, f y)+d(y, f x)]},\right. \\
\\
\frac{d+s d(x, f x)+s^{3}[d(y, f x)+d(y, f y)]}{1+s d(x, y)},
\end{gathered}
$$

and

$$
N(x, y)=\min \{d(x, f x), d(y, f y), d(x, f y), d(y, f x)\} .
$$

Lemma 2.1. Let $(X, d)$ be a b-metric space with coefficient $\mathrm{s} \geqslant 1$ and $\mathrm{f}: \mathrm{X} \rightarrow \mathrm{X}$ be a mapping. Suppose that $\left\{x_{\mathrm{n}}\right\}$ is a sequence in $\mathrm{X}$ induced by $\mathrm{x}_{\mathrm{n}+1}=\mathrm{f} \mathrm{x}_{\mathrm{n}}$ such that

$$
d\left(x_{n}, x_{n+1}\right) \leqslant k d\left(x_{n-1}, x_{n}\right)
$$

for all $\mathrm{n} \in \mathbb{N}$, where $\mathrm{k} \in[0,1)$ is a constant. Then $\left\{x_{\mathrm{n}}\right\}$ is a b-Cauchy sequence. 
Proof. Let $x_{0} \in X$ and $x_{n+1}=f x_{n}$ for all $n \in \mathbb{N} \cup\{0\}$. We divide the proof into three cases.

Case 1 . Let $k \in\left[0, \frac{1}{s}\right)(s>1)$. By the hypothesis, we have

$$
d\left(x_{n}, x_{n+1}\right) \leqslant k d\left(x_{n-1}, x_{n}\right) \leqslant k^{2} d\left(x_{n-2}, x_{n-1}\right) \leqslant \cdots \leqslant k^{n} d\left(x_{0}, x_{1}\right) .
$$

Thus, for any $n>m$, we have

$$
\begin{aligned}
d\left(x_{m}, x_{n}\right) \leqslant & s\left[d\left(x_{m}, x_{m+1}\right)+d\left(x_{m+1}, x_{n}\right)\right] \\
\leqslant & s d\left(x_{m}, x_{m+1}\right)+s^{2}\left[d\left(x_{m+1}, x_{m+2}\right)+d\left(x_{m+2}, x_{n}\right)\right] \\
\leqslant & s d\left(x_{m}, x_{m+1}\right)+s^{2} d\left(x_{m+1}, x_{m+2}\right)+s^{3}\left[d\left(x_{m+2}, x_{m+3}\right)+d\left(x_{m+3}, x_{n}\right)\right] \\
\leqslant & s d\left(x_{m}, x_{m+1}\right)+s^{2} d\left(x_{m+1}, x_{m+2}\right)+s^{3} d\left(x_{m+2}, x_{m+3}\right) \\
& +\cdots+s^{n-m-1} d\left(x_{n-2}, x_{n-1}\right)+s^{n-m-1} d\left(x_{n-1}, x_{n}\right) \\
\leqslant & s k^{m} d\left(x_{0}, x_{1}\right)+s^{2} k^{m+1} d\left(x_{0}, x_{1}\right)+s^{3} k^{m+2} d\left(x_{0}, x_{1}\right) \\
& +\cdots+s^{n-m-1} k^{n-2} d\left(x_{0}, x_{1}\right)+s^{n-m-1} k^{n-1} d\left(x_{0}, x_{1}\right) \\
\leqslant & s k^{m}\left(1+s k+s^{2} k^{2}+\cdots+s^{n-m-2} k^{n-m-2}+s^{n-m-1} k^{n-m-1}\right) d\left(x_{0}, x_{1}\right) \\
\leqslant & s k^{m}\left[\sum_{i=0}^{\infty}(s k)^{i}\right] d\left(x_{0}, x_{1}\right) \\
= & \frac{s k^{m}}{1-s k} d\left(x_{0}, x_{1}\right) \rightarrow 0(m \rightarrow \infty)
\end{aligned}
$$

which implies that $\left\{x_{n}\right\}$ is a b-Cauchy sequence. In other words, $\left\{f^{n} x_{0}\right\}$ is a b-Cauchy sequence.

Case 2. Let $k \in\left[\frac{1}{s}, 1\right)(s>1)$. In this case, we have $k^{n} \rightarrow 0$ as $n \rightarrow \infty$, then there is $n_{0} \in \mathbb{N}$ such that $k^{n_{0}}<\frac{1}{s}$. Thus, by Case 1 , we claim that

$$
\left\{\left(f^{\mathfrak{n}_{0}}\right)^{\mathrm{n}_{1}} x_{0}\right\}_{\mathfrak{n}=0}^{\infty}:=\left\{x_{n_{0}}, x_{n_{0}+1}, x_{n_{0}+2}, \ldots, x_{n_{0}+n}, \ldots\right\}
$$

is a b-Cauchy sequence. Then

$$
\left\{x_{n}\right\}_{\mathfrak{n}=0}^{\infty}=\left\{x_{0}, x_{1}, x_{2}, \ldots, x_{n_{0}-1}\right\} \cup\left\{x_{n_{0}}, x_{n_{0}+1}, x_{n_{0}+2}, \ldots, x_{n_{0}+n}, \ldots\right\}
$$

is a b-Cauchy sequence in $X$.

Case 3. Let $s=1$, then $(X, d)$ is a metric space. In this case, the result is valid and hence we omit the proof.

Remark 2.2. Lemma 2.1 extends $k \in\left[0, \frac{1}{s}\right)$ to $k \in[0,1)$, and hence it generalizes [9, Lemma 3.1], [11, Lemma 2.19], and [19, Lemma 3.1].

Theorem 2.3. Let $(\mathrm{X}, \mathrm{d})$ be $\mathrm{a}$ b-complete $\mathrm{b}$-metric space with coefficient $\mathrm{s}>1$ and $\mathrm{f}: \mathrm{X} \rightarrow \mathrm{X}$ be a mapping such that

$$
\psi\left(s^{\alpha} d(f x, f y)\right) \leqslant F\left(\psi\left(M_{i}(x, y)\right), \varphi\left(M_{i}(x, y)\right)\right)+\beta N(x, y)
$$

for all $x, y \in X$, where $\alpha>0, \beta \geqslant 0$ are constants, $\psi, \varphi: \mathbb{R}^{+} \rightarrow \mathbb{R}^{+}$are altering distance functions, $F$ : $\mathbb{R}^{+} \times \mathbb{R}^{+} \rightarrow \mathbb{R}$ is a C-class function, and $\mathrm{M}_{i}(x, y)(i=1,2,3)$ and $\mathrm{N}(\mathrm{x}, \mathrm{y})$ are defined by (2.1)-(2.4). Then for each $i \in\{1,2,3\}$, f has a unique fixed point in $X$. Moreover, for any $x \in X$, the iterative sequence $\left\{\mathrm{f}^{\mathrm{n}} \mathrm{x}\right\}(\mathrm{n} \in \mathbb{N})$ $\mathrm{b}$-converges to the fixed point.

Proof. Choose $x_{0} \in X$ and construct a Picard iterative sequence $\left\{x_{n}\right\}$ by $x_{n+1}=f x_{n}(n \in \mathbb{N} \cup\{0\})$. If there exists $n_{0} \in \mathbb{N}$ such that $x_{n_{0}}=x_{n_{0}+1}$, then $x_{n_{0}}=x_{n_{0}+1}=f x_{n_{0}}$. In this case, $x_{n_{0}}$ is a fixed point of $f$. Next, 
without loss of generality, let $x_{n} \neq x_{n+1}$ for all $n \in \mathbb{N} \cup\{0\}$. From (2.5), we have

$$
\begin{aligned}
\psi\left(s^{\alpha} d\left(x_{n}, x_{n+1}\right)\right) & =\psi\left(s^{\alpha} d\left(f x_{n-1}, f x_{n}\right)\right) \\
& \leqslant F\left(\psi\left(M_{i}\left(x_{n-1}, x_{n}\right)\right), \varphi\left(M_{i}\left(x_{n-1}, x_{n}\right)\right)\right)+\beta N\left(x_{n-1}, x_{n}\right) \\
& \leqslant \psi\left(M_{i}\left(x_{n-1}, x_{n}\right)\right)+\beta N\left(x_{n-1}, x_{n}\right)
\end{aligned}
$$

where

$$
\begin{aligned}
M_{1}\left(x_{n}, x_{n-1}\right) & =\max \left\{d\left(x_{n}, x_{n-1}\right), \frac{d\left(x_{n}, x_{n+1}\right) d\left(x_{n-1}, x_{n}\right)}{1+d\left(x_{n}, x_{n-1}\right)}, \frac{d\left(x_{n}, x_{n+1}\right) d\left(x_{n-1}, x_{n}\right)}{1+d\left(x_{n+1}, x_{n}\right)}\right\} \\
& \leqslant \max \left\{d\left(x_{n}, x_{n-1}\right), \frac{d\left(x_{n}, x_{n+1}\right) d\left(x_{n-1}, x_{n}\right)}{d\left(x_{n}, x_{n-1}\right)}, \frac{d\left(x_{n}, x_{n+1}\right) d\left(x_{n-1}, x_{n}\right)}{d\left(x_{n+1}, x_{n}\right)}\right\} \\
& =\max \left\{d\left(x_{n}, x_{n-1}\right), d\left(x_{n}, x_{n+1}\right)\right\},
\end{aligned}
$$

$$
\begin{aligned}
& M_{2}\left(x_{n}, x_{n-1}\right) \\
& =\max \left\{d\left(x_{n}, x_{n-1}\right), \frac{d\left(x_{n}, x_{n+1}\right) d\left(x_{n}, x_{n}\right)+d\left(x_{n-1}, x_{n}\right) d\left(x_{n-1}, x_{n+1}\right)}{1+s\left[d\left(x_{n}, x_{n+1}\right)+d\left(x_{n-1}, x_{n}\right)\right]},\right. \\
& \left.\quad \frac{d\left(x_{n}, x_{n+1}\right) d\left(x_{n}, x_{n}\right)+d\left(x_{n-1}, x_{n}\right) d\left(x_{n-1}, x_{n+1}\right)}{1+s\left[d\left(x_{n}, x_{n}\right)+d\left(x_{n-1}, x_{n+1}\right)\right]}\right\} \\
& =\max \left\{d\left(x_{n}, x_{n-1}\right), \frac{d\left(x_{n-1}, x_{n}\right) d\left(x_{n-1}, x_{n+1}\right)}{1+s\left[d\left(x_{n}, x_{n+1}\right)+d\left(x_{n-1}, x_{n}\right)\right]}, \frac{d\left(x_{n-1}, x_{n}\right) d\left(x_{n-1}, x_{n+1}\right)}{1+s d\left(x_{n-1}, x_{n+1}\right)}\right\} \\
& \leqslant \max \left\{d\left(x_{n}, x_{n-1}\right), \frac{s d\left(x_{n-1}, x_{n}\right)\left[d\left(x_{n-1}, x_{n}\right)+d\left(x_{n}, x_{n+1}\right)\right]}{1+s\left[d\left(x_{n}, x_{n+1}\right)+d\left(x_{n-1}, x_{n}\right)\right]}, \frac{d\left(x_{n-1}, x_{n}\right) d\left(x_{n-1}, x_{n+1}\right)}{s d\left(x_{n-1}, x_{n+1}\right)}\right\} \\
& \leqslant \max \left\{d\left(x_{n}, x_{n-1}\right), \frac{s d\left(x_{n-1}, x_{n}\right)\left[d\left(x_{n-1}, x_{n}\right)+d\left(x_{n}, x_{n+1}\right)\right]}{s\left[d\left(x_{n}, x_{n+1}\right)+d\left(x_{n-1}, x_{n}\right)\right]}, \frac{d\left(x_{n}, x_{n-1}\right)}{s}\right\} \\
& \leqslant d\left(x_{n}, x_{n-1}\right),
\end{aligned}
$$

$$
\begin{aligned}
M_{3}\left(x_{n}, x_{n-1}\right)= & \max \left\{d\left(x_{n}, x_{n-1}\right), \frac{d\left(x_{n}, x_{n+1}\right) d\left(x_{n-1}, x_{n}\right)}{1+s\left[d\left(x_{n}, x_{n-1}\right)+d\left(x_{n}, x_{n}\right)+d\left(x_{n-1}, x_{n+1}\right)\right]},\right. \\
& \left.\frac{d\left(x_{n}, x_{n}\right) d\left(x_{n}, x_{n-1}\right)}{1+s d\left(x_{n}, x_{n+1}\right)+s^{3}\left[d\left(x_{n-1}, x_{n+1}\right)+d\left(x_{n-1}, x_{n}\right)\right]}\right\} \\
& \max \left\{d\left(x_{n}, x_{n-1}\right), \frac{d\left(x_{n}, x_{n+1}\right) d\left(x_{n-1}, x_{n}\right)}{1+s\left[d\left(x_{n}, x_{n-1}\right)+d\left(x_{n-1}, x_{n+1}\right)\right]}, 0\right\} \\
\leqslant & \max \left\{d\left(x_{n}, x_{n-1}\right), \frac{d\left(x_{n}, x_{n+1}\right) d\left(x_{n-1}, x_{n}\right)}{d\left(x_{n}, x_{n-1}\right)}\right\} \\
= & \max \left\{d\left(x_{n}, x_{n-1}\right), d\left(x_{n}, x_{n+1}\right)\right\},
\end{aligned}
$$

and

$$
\begin{aligned}
N\left(x_{n}, x_{n-1}\right) & =\min \left\{d\left(x_{n}, f x_{n}\right), d\left(x_{n-1}, f x_{n-1}\right), d\left(x_{n}, f x_{n-1}\right), d\left(x_{n-1}, f x_{n}\right)\right\} \\
& =\min \left\{d\left(x_{n}, x_{n+1}\right), d\left(x_{n-1}, x_{n}\right), 0, d\left(x_{n-1}, x_{n+1}\right)\right\}=0 .
\end{aligned}
$$

Next we prove

$$
d\left(x_{n}, x_{n+1}\right) \leqslant \frac{1}{s^{\alpha}} d\left(x_{n-1}, x_{n}\right)
$$

for all $n \in \mathbb{N}$. 
If $M_{i}=M_{1}$, then by (2.6), (2.7), and (2.10), it follows that

$$
\psi\left(s^{\alpha} d\left(x_{n}, x_{n+1}\right)\right) \leqslant \psi\left(M_{1}\left(x_{n-1}, x_{n}\right)\right) \leqslant \psi\left(\max \left\{d\left(x_{n}, x_{n-1}\right), d\left(x_{n}, x_{n+1}\right)\right\}\right) .
$$

Since $\psi$ is monotone, then it is easy to see from (2.12) that

$$
s^{\alpha} d\left(x_{n}, x_{n+1}\right) \leqslant \max \left\{d\left(x_{n}, x_{n-1}\right), d\left(x_{n}, x_{n+1}\right)\right\} .
$$

If $d\left(x_{n}, x_{n-1}\right)<d\left(x_{n}, x_{n+1}\right)$, then by (2.13) it yields that

$$
d\left(x_{n}, x_{n+1}\right)<\frac{1}{s^{\alpha}} d\left(x_{n}, x_{n+1}\right)<d\left(x_{n}, x_{n+1}\right) .
$$

This is a contradiction. Hence, $d\left(x_{n}, x_{n-1}\right) \geqslant d\left(x_{n}, x_{n+1}\right)$. Again by (2.13), it implies (2.11).

If $M_{i}=M_{2}$, then by (2.6), (2.8), and (2.10), it is obvious that

$$
\psi\left(s^{\alpha} d\left(x_{n}, x_{n+1}\right)\right) \leqslant \psi\left(M_{2}\left(x_{n-1}, x_{n}\right)\right) \leqslant \psi\left(d\left(x_{n}, x_{n-1}\right)\right) .
$$

Again by the monotonicity of $\psi,(2.11)$ holds.

If $M_{i}=M_{3}$, then by (2.6), (2.9), and (2.10) together with the case of $M_{i}=M_{1}$ mentioned above, we get (2.11).

As a consequence, by (2.11) and Lemma 2.1, we say $\left\{x_{n}\right\}$ is a b-Cauchy sequence. Since $(X, d)$ is b-complete, then $x_{n} \rightarrow u(n \rightarrow \infty)$ for some $u \in X$.

Subsequently, we prove that $u$ is a fixed point of $f$. As a matter of fact, by the triangle inequality, we have

$$
\frac{1}{s} d(u, f u) \leqslant d\left(u, x_{n+1}\right)+d\left(f x_{n}, f u\right) .
$$

Now by (2.5), we arrive at

$$
\psi\left(s^{\alpha} d\left(f x_{n}, f u\right)\right) \leqslant F\left(\psi\left(M_{i}\left(x_{n}, u\right)\right), \varphi\left(M_{i}\left(x_{n}, u\right)\right)\right)+\beta N\left(x_{n}, u\right),
$$

where

$$
\begin{gathered}
M_{1}\left(x_{n}, u\right)=\max \left\{d\left(x_{n}, u\right), \frac{d\left(x_{n}, x_{n+1}\right) d(u, f u)}{1+d\left(x_{n}, u\right)}, \frac{d\left(x_{n}, x_{n+1}\right) d(u, f u)}{1+d\left(x_{n+1}, f u\right)}\right\} \\
\rightarrow \max \{0,0,0\}=0(n \rightarrow \infty), \\
M_{2}\left(x_{n}, u\right)=\max \left\{d\left(x_{n}, u\right), \frac{d\left(x_{n}, x_{n+1}\right) d\left(x_{n}, f u\right)+d(u, f u) d\left(u, x_{n+1}\right)}{1+s\left[d\left(x_{n}, x_{n+1}\right)+d(u, f u)\right]},\right. \\
\left.\quad \frac{d\left(x_{n}, x_{n+1}\right) d\left(x_{n}, f u\right)+d(u, f u) d\left(u, x_{n+1}\right)}{1+s\left[d\left(x_{n}, f u\right)+d\left(u, x_{n+1}\right)\right]}\right\} \\
\leqslant \max \left\{d\left(x_{n}, u\right), d\left(x_{n}, x_{n+1}\right) s\left[d\left(x_{n}, u\right)+d(u, f u)\right]+d(u, f u) d\left(u, x_{n+1}\right),\right. \\
\rightarrow \max \{0,0 \cdot s[0+d(u, f u)]+d(u, f u) \cdot 0,0 \cdot s[0+d(u, f u)]+d(u, f u) \cdot 0\} \\
=0(n \rightarrow \infty), \\
M_{3}\left(x_{n}, u\right) \leqslant \max \left\{d\left(x_{n}, u\right), d\left(x_{n}, x_{n+1}\right) d(u, f u), s\left[d\left(x_{n}, u\right)+d(u, f u)\right] d\left(x_{n}, u\right)\right\} \\
\rightarrow \max \{0,0 \cdot d(u, f u), s \cdot[0+d(u, f u)] \cdot 0\}=0(n \rightarrow \infty),
\end{gathered}
$$

and

$$
\begin{aligned}
N\left(x_{n}, u\right) & =\min \left\{d\left(x_{n}, x_{n+1}\right), d(u, f u), d\left(x_{n}, f u\right), d\left(u, x_{n+1}\right)\right\} \\
& \leqslant \min \left\{d\left(x_{n}, x_{n+1}\right), d(u, f u), s\left[d\left(x_{n}, u\right)+d(u, f u)\right], d\left(u, x_{n+1}\right)\right\} \\
& \rightarrow \min \{0, d(u, f u), s d(u, f u), 0\}=0(n \rightarrow \infty) .
\end{aligned}
$$

In view of the continuity of $F, \psi$, and $\varphi$, take the limit as $n \rightarrow \infty$ from both sides of (2.15), it follows 
immediately from (2.15)-(2.19) that

$$
\begin{aligned}
\psi\left(s^{\alpha} \lim _{n \rightarrow \infty} d\left(f x_{n}, f u\right)\right) & \leqslant F\left(\psi\left(\lim _{n \rightarrow \infty} M_{i}\left(x_{n}, u\right)\right), \varphi\left(\lim _{n \rightarrow \infty} M_{i}\left(x_{n}, u\right)\right)\right)+\beta \lim _{n \rightarrow \infty} N\left(x_{n}, u\right) \\
& \leqslant F(\psi(0), \varphi(0)) \leqslant \psi(0) .
\end{aligned}
$$

By (2.20) and the monotonicity of $\psi$, we deduce that

$$
s^{\alpha} \lim _{n \rightarrow \infty} d\left(f x_{n}, f u\right) \leqslant 0,
$$

which means that

$$
\lim _{n \rightarrow \infty} d\left(f x_{n}, f u\right)=0 .
$$

Taking the limit as $n \rightarrow \infty$ from both sides of (2.14) and using (2.21), we conclude that $\frac{1}{s} d(u, f u) \leqslant 0$. So $u=f u$. That is, $u$ is a fixed point of $f$.

Finally, we prove that the fixed point of $f$ is unique. To this end, suppose that $f$ has another fixed point $v$, i.e., $v=f v$. Then by (2.5), it is clear that

$$
\psi\left(s^{\alpha} d(f u, f v)\right) \leqslant F\left(\psi\left(M_{i}(u, v)\right), \varphi\left(M_{i}(u, v)\right)\right)+\beta N(u, v),
$$

where

$$
\begin{gathered}
M_{1}(u, v)=\max \left\{d(u, v), \frac{d(u, f u) d(v, f v)}{1+d(u, v)}, \frac{d(u, f u) d(v, f v)}{1+d(f u, f v)}\right\}=d(u, v), \\
M_{2}(u, v)=\max \left\{d(u, v), \frac{d(u, f u) d(u, f v)+d(v, f v) d(v, f u)}{1+s[d(u, f u)+d(v, f v)]},\right. \\
\left.\frac{d(u, f u) d(u, f v)+d(v, f v) d(v, f u)}{1+s[d(u, f v)+d(v, f u)]}\right\}=d(u, v), \\
M_{3}(u, v)=\max \left\{d(u, v), \frac{d(u, f u) d(v, f v)}{1+s[d(u, v)+d(u, f v)+d(v, f u)]},\right. \\
\left.\frac{d(u, f v) d(u, v)}{1+s d(u, f u)+s^{3}[d(v, f u)+d(v, f v)]}\right\}=d(u, v),
\end{gathered}
$$

and

$$
N(u, v)=\min \{d(u, f u), d(v, f v), d(u, f v), d(v, f u)\}=0 .
$$

By (2.22)-(2.26), it may be verified that

$$
\psi\left(s^{\alpha} d(u, v)\right) \leqslant F(\psi(d(u, v)), \varphi(d(u, v))) \leqslant \psi(d(u, v)) .
$$

By virtue of (2.27) and the monotonicity of $\psi$, it follows that

$$
s^{\alpha} d(u, v) \leqslant d(u, v) .
$$

Therefore, $d(u, v)=0$, i.e., $u=v$.

Corollary 2.4. Let $(\mathrm{X}, \mathrm{d})$ be a b-complete b-metric space with coefficient $\mathrm{s}>1$ and $\mathrm{f}: \mathrm{X} \rightarrow \mathrm{X}$ be a mapping such that

$$
\psi\left(s^{\alpha} d(f x, f y)\right) \leqslant \psi\left(M_{i}(x, y)\right)-\varphi\left(M_{i}(x, y)\right)+\beta N(x, y)
$$

for all $x, y \in X$, where $\alpha>0, \beta \geqslant 0$ are constants, $\psi, \varphi: \mathbb{R}^{+} \rightarrow \mathbb{R}^{+}$are altering distance functions, and $M_{i}(x, y)(i=1,2,3)$ and $N(x, y)$ are defined by (2.1)-(2.4). Then for each $i \in\{1,2,3\}$, f has a unique fixed point in $X$. Moreover, for any $x \in X$, the iterative sequence $\left\{\mathrm{f}^{\mathrm{n}} \mathrm{x}\right\}(\mathrm{n} \in \mathbb{N})$ b-converges to the fixed point. 
Proof. Taking $F(s, t)=s-t(s, t \geqslant 0)$ in Theorem 2.3, we obtain the desired result.

Corollary 2.5. Let $(\mathrm{X}, \mathrm{d})$ be a $\mathrm{b}$-complete $\mathrm{b}$-metric space with coefficient $\mathrm{s}>1$ and $\mathrm{f}: \mathrm{X} \rightarrow \mathrm{X}$ be a mapping such that

$$
\psi\left(s^{\alpha} d(f x, f y)\right) \leqslant \psi\left(M_{i}(x, y)\right) \phi\left(\varphi\left(M_{i}(x, y)\right)\right)+\beta N(x, y)
$$

for all $x, y \in X$, where $\alpha>0, \beta \geqslant 0$ are constants, $\psi, \varphi: \mathbb{R}^{+} \rightarrow \mathbb{R}^{+}$are altering distance functions, $\phi: \mathbb{R}^{+} \rightarrow$ $[0,1)$ is a continuous function, and $M_{i}(x, y)(i=1,2,3)$ and $N(x, y)$ are defined by (2.1)-(2.4). Then for each $i \in\{1,2,3\}$, $f$ has a unique fixed point in $X$. Moreover, for any $x \in X$, the iterative sequence $\left\{f^{n} x\right\}(n \in \mathbb{N})$ b-converges to the fixed point.

Proof. Take $\mathrm{F}(\mathrm{s}, \mathrm{t})=s \phi(\mathrm{t})(\mathrm{s}, \mathrm{t} \geqslant 0)$ in Theorem 2.3, the proof is completed.

Corollary 2.6. Let $(\mathrm{X}, \mathrm{d})$ be a b-complete b-metric space with coefficient $\mathrm{s}>1$ and $\mathrm{f}: \mathrm{X} \rightarrow \mathrm{X}$ be a mapping such that

$$
s^{\alpha} d(f x, f y) \leqslant \theta\left(M_{i}(x, y)\right)+\beta N(x, y)
$$

for all $x, y \in X$, where $\alpha>0, \beta \geqslant 0$ are constants, $\theta: \mathbb{R}^{+} \rightarrow \mathbb{R}^{+}$is a continuous function satisfying $\theta(t)<t$ for all $\mathrm{t}>0$, and $\mathrm{M}_{\mathrm{i}}(\mathrm{x}, \mathrm{y})(\mathrm{i}=1,2,3)$ and $\mathrm{N}(\mathrm{x}, \mathrm{y})$ are defined by (2.1)-(2.4). Then for each $\mathrm{i} \in\{1,2,3\}$, $\mathrm{f}$ has a unique fixed point in $X$. Moreover, for any $x \in X$, the iterative sequence $\left\{f^{n} x\right\}(n \in \mathbb{N})$ b-converges to the fixed point.

Proof. Take $F(s, t)=\theta(s)(s, t \geqslant 0)$ and $\psi(t)=t(t \geqslant 0)$ in Theorem 2.3, the proof is finished.

Corollary 2.7. Let $(\mathrm{X}, \mathrm{d})$ be a b-complete b-metric space with coefficient $\mathrm{s}>1$ and $\mathrm{f}: \mathrm{X} \rightarrow \mathrm{X}$ be a mapping such that

$$
s^{\alpha} d(f x, f y) \leqslant \frac{M_{i}(x, y)}{1+M_{i}(x, y)}
$$

for all $x, y \in X$, where $\alpha>0$ is a constant, and $M_{i}(x, y)(i=1,2,3)$ are defined by (2.1)-(2.3). Then for each $i \in\{1,2,3\}$, $f$ has a unique fixed point in $X$. Moreover, for any $x \in X$, the iterative sequence $\left\{f^{n} x\right\}(n \in \mathbb{N})$ $\mathrm{b}$-converges to the fixed point.

Proof. Take $\theta(s)=\frac{s}{1+s}(s \geqslant 0)$ and $\beta=0$ in Corollary 2.6, the claim holds.

Corollary 2.8. Let $(\mathrm{X}, \mathrm{d})$ be a b-complete b-metric space with coefficient $\mathrm{s}>1$ and $\mathrm{f}: \mathrm{X} \rightarrow \mathrm{X}$ be a mapping such that

$$
s^{\alpha} d(f x, f y) \leqslant \ln \left(1+M_{i}(x, y)\right)
$$

for all $x, y \in X$, where $\alpha>0$ is a constant, and $M_{i}(x, y)(i=1,2,3)$ are defined by (2.1)-(2.3). Then for each $i \in\{1,2,3\}$, $f$ has a unique fixed point in $X$. Moreover, for any $x \in X$, the iterative sequence $\left\{f^{n} x\right\}(n \in \mathbb{N})$ $\mathrm{b}$-converges to the fixed point.

Proof. Take $\theta(s)=\ln (1+s)(s \geqslant 0)$ and $\beta=0$ in Corollary 2.6, it finishes the proof.

Corollary 2.9. Let $(\mathrm{X}, \mathrm{d})$ be a b-complete b-metric space with coefficient $\mathrm{s}>1$ and $\mathrm{f}: \mathrm{X} \rightarrow \mathrm{X}$ be a mapping such that

$$
s^{\alpha} d(f x, f y) \leqslant \lambda M_{i}(x, y)
$$

for all $x, y \in X$, where $\alpha>0$ and $0<\lambda<1$ are constants, and $M_{i}(x, y)(i=1,2,3)$ are defined by (2.1)-(2.3). Then for each $i \in\{1,2,3\}$, f has a unique fixed point in $X$. Moreover, for any $x \in X$, the iterative sequence $\left\{f^{n} x\right\}(n \in \mathbb{N})$ $\mathrm{b}$-converges to the fixed point.

Proof. Take $\theta(s)=\lambda s(s \geqslant 0)$ and $\beta=0$ in Corollary 2.6, this completes the proof. 
Remark 2.10. Our theorems and corollaries contain weak conditions. The proof of Theorem 2.3 never use Lemma 1.12 since we dismiss the problem of whether the b-metric being continuous or discontinuous. However, some previous result strongly lies on the discontinuity of b-metric, and hence they frequently have to use Lemma 1.12 (see [1, 15, 20-23]).

Remark 2.11. In Theorem 2.3 and Corollaries 2.4-2.9, we assume that the range of the coefficient $\alpha$ is $\alpha>0$ instead of $\alpha>1$. In fact, by Lemma 2.1 and Remark 2.2, $\alpha>0$ is sufficient.

Example 2.12. Let $X=\{1,2,4\}$, and define a mapping $d: X \times X \rightarrow \mathbb{R}^{+}$by

$$
d(x, y)= \begin{cases}|x-y|^{-1}, & \text { if } x \neq y \\ 0, & \text { if } x=y\end{cases}
$$

It is easy to see that $(X, d)$ is a b-complete $b$-metric space with coefficient $s=\frac{6}{5}$. Assume that $f: X \rightarrow X$ is a mapping such that $f 1=4, f 2=1, f 4=4$. Simple calculations show that $\operatorname{sd}(f x, f y) \leqslant \frac{4}{5} M_{i}(x, y)$ $(i=1,2,3)$ hold for all $x, y \in X$. Thus, all conditions of Corollary 2.9 are satisfied and then $f$ has a unique fixed point $x=4$ in $X$.

Example 2.13. Let $X$ be the set of Lebesgue measurable functions on $[0,1]$ such that $\int_{0}^{1} x(t) d t<1$. Define $\mathrm{d}: \mathrm{X} \times \mathrm{X} \rightarrow \mathbb{R}^{+}$by

$$
d(x, y)=\int_{0}^{1}|x(t)-y(t)|^{2} d t
$$

Then $(X, d)$ is a b-complete $b$-metric space with coefficient $s=2$. Define the mapping $f: X \rightarrow X$ by

$$
f x(t)=\frac{1}{2} \ln (1+|x(t)|) \text {. }
$$

Let $0<\alpha<2$ be a constant, then

$$
\begin{aligned}
s^{\alpha} d(f x, f y) & =2^{\alpha} \int_{0}^{1}|f x(t)-f y(t)|^{2} d t \\
& =2^{\alpha} \int_{0}^{1}\left|\frac{1}{2} \ln (1+|x(t)|)-\frac{1}{2} \ln (1+|y(t)|)\right|^{2} d t \\
& =2^{\alpha-2} \int_{0}^{1}\left|\ln \left(\frac{1+|x(t)|}{1+|y(t)|}\right)\right|^{2} d t \\
& =2^{\alpha-2} \int_{0}^{1}\left|\ln \left(1+\frac{|x(t)|-|y(t)|}{1+|y(t)|}\right)\right|^{2} d t \\
& \leqslant 2^{\alpha-2} \int_{0}^{1}\left|\ln \left(1+\frac{|x(t)-y(t)|}{1+|y(t)|}\right)\right|^{2} d t \\
& \leqslant 2^{\alpha-2} \int_{0}^{1}|x(t)-y(t)|^{2} d t=2^{\alpha-2} d(x, y) \leqslant 2^{\alpha-2} M_{i}(x, y) .
\end{aligned}
$$

Consequently, all conditions of Corollary 2.9 are satisfied and then $f$ has a unique fixed point in X.

\section{Applications}

In this section, we first apply Theorem 2.3 to solve the second-order initial value problem:

$$
\left\{\begin{array}{l}
\frac{d^{2} y}{d x^{2}}+\phi_{1}(x) \frac{d y}{d x}+\phi_{2}(x) y=q(x), \quad x \in\left[0, x_{0}\right], \\
y(0)=C_{0}, y^{\prime}(0)=C_{1},
\end{array}\right.
$$

where $\phi_{1}(x), \phi_{2}(x), q(x) \in C\left(\left[0, x_{0}\right]\right)$ (the set of all continuous real functions defined on $\left[0, x_{0}\right]$ ) are given, and $\mathrm{C}_{0}, \mathrm{C}_{1}$ are constants. 
Theorem 3.1. Consider initial value problem (3.1), and set $M=\max _{0 \leqslant t, x \leqslant x_{0}}\left|\phi_{2}(x)(t-x)-\phi_{1}(x)\right|$. If $2^{\alpha} x_{0}{ }^{2} M^{2}<1$ is satisfied for some $\alpha>0$, then (3.1) has a unique solution in $\mathrm{C}\left(\left[0, x_{0}\right]\right)$. Further, the solution is written as follows:

$$
y=\sum_{n=0}^{\infty} \int_{0}^{x}(x-t) u_{n}(t) d t+C_{1} x+C_{0},
$$

where

$$
\begin{aligned}
u_{0}(x) & =q(x)-C_{1} \phi_{1}(x)-C_{1} x \phi_{2}(x)-C_{0} \phi_{2}(x) \\
u_{n}(x) & =\int_{0}^{x}\left[\phi_{2}(x)(t-x)-\phi_{1}(x)\right] u_{n-1}(t) d t, \quad n=1,2, \ldots
\end{aligned}
$$

Proof. Put $u(x)=\frac{d^{2} y}{d x^{2}}, p(x)=\frac{d y}{d x}$, then $u(x), p(x) \in C\left(\left[0, x_{0}\right]\right)$. Considering the initial conditions, we get that

$$
\begin{aligned}
\frac{d y}{d x} & =\int_{0}^{x} u(t) d t+C_{1}, \\
y=\int_{0}^{x} p(s) d s+C_{0} & =\int_{0}^{x}\left[\int_{0}^{s} u(t) d t+C_{1}\right] d s+C_{0} \\
& =\int_{0}^{x} \int_{0}^{s} u(t) d t d s+C_{1} x+C_{0} \\
& =\int_{0}^{x} d t \int_{t}^{x} u(t) d s+C_{1} x+C_{0}=\int_{0}^{x}(x-t) u(t) d t+C_{1} x+C_{0} .
\end{aligned}
$$

Substituting (3.2) and (3.3) into (3.1), we obtain that (3.1) is equivalent to the following Volterra type integral equation:

$$
u(x)=\int_{0}^{x} K(x, t) u(t) d t+Q(x),
$$

where $\mathrm{K}(\mathrm{x}, \mathrm{t})=\phi_{2}(\mathrm{x})(\mathrm{t}-\mathrm{x})-\phi_{1}(\mathrm{x}), \mathrm{Q}(\mathrm{x})=\mathrm{q}(\mathrm{x})-\mathrm{C}_{1} \phi_{1}(\mathrm{x})-\mathrm{C}_{1} \mathrm{x} \phi_{2}(\mathrm{x})-\mathrm{C}_{0} \phi_{2}(\mathrm{x})$.

Let $X=C\left(\left[0, x_{0}\right]\right)$. Put $d: X \times X \rightarrow \mathbb{R}^{+}$as $d(u, v)=\max _{0 \leqslant x \leqslant x_{0}}|u(x)-v(x)|^{2}$. It is clear that $(X, d)$ is a $b$-complete $b$-metric space with coefficient $s=2$.

Define a mapping $f: X \rightarrow X$ by

$$
f u(x)=\int_{0}^{x} K(x, t) u(t) d t+Q(x)
$$

For any $u, v \in C\left(\left[0, x_{0}\right]\right)$, we have

$$
\begin{aligned}
\mathrm{d}(\mathrm{fu}, \mathrm{fv}) & =\max _{0 \leqslant x \leqslant x_{0}}\left|\int_{0}^{x} \mathrm{~K}(\mathrm{x}, \mathrm{t}) \mathrm{u}(\mathrm{t}) \mathrm{dt}-\int_{0}^{x} \mathrm{~K}(\mathrm{x}, \mathrm{t}) v(\mathrm{t}) \mathrm{dt}\right|^{2} \\
& =\max _{0 \leqslant x \leqslant x_{0}}\left|\int_{0}^{x} K(x, \mathrm{t})[\mathrm{u}(\mathrm{t})-v(\mathrm{t})] \mathrm{dt}\right|^{2} \\
& \leqslant x_{0}{ }^{2} \mathrm{M}^{2} \max _{0 \leqslant \mathrm{t} \leqslant x_{0}}|\mathrm{u}(\mathrm{t})-v(\mathrm{t})|^{2} \\
& =x_{0}{ }^{2} \mathrm{M}^{2} \mathrm{~d}(\mathrm{u}, v) .
\end{aligned}
$$

Let $\psi(t)=\frac{1}{s^{\alpha}} t(t \geqslant 0), F(\xi, \eta)=s^{\alpha} x_{0}^{2} M^{2} \xi(\xi, \eta \geqslant 0)$, then $\psi$ is an altering distance function and $F$ is 
a C-class function because of $s^{\alpha} x_{0}^{2} M^{2}=2^{\alpha} x_{0}^{2} M^{2}<1$. Otherwise, by (3.4), we have

$$
\begin{aligned}
\psi\left(s^{\alpha} d(f u, f v)\right) & =d(f u, f v) \\
& \leqslant x_{0}{ }^{2} M^{2} d(u, v) \\
& =s^{\alpha} x_{0}{ }^{2} M^{2} \psi(d(u, v)) \\
& \leqslant s^{\alpha} x_{0}{ }^{2} M^{2} \psi\left(M_{i}(u, v)\right) \\
& =F\left(\psi\left(M_{i}(x, y)\right), \varphi\left(M_{i}(x, y)\right)\right)+\beta N(x, y),
\end{aligned}
$$

where $\beta=0, \varphi: \mathbb{R}^{+} \rightarrow \mathbb{R}^{+}$is any altering distance function.

Owing to the above statement, all conditions of Theorem 2.3 are satisfied, then by Theorem $2.3, f$ has a unique fixed point in $X$. That is to say, the initial value problem (3.1) has a unique solution in $C\left(\left[0, x_{0}\right]\right)$.

Eventually, we look for the expression of solution. To this end, take

$$
y_{n}(x)=\sum_{i=0}^{n} u_{i}(x), \quad x \in\left[0, x_{0}\right]
$$

where

Note that

$$
u_{0}(x)=Q(x), \quad u_{i}(x)=\int_{0}^{x} K(x, t) u_{i-1}(t) d t, i=1,2, \ldots
$$

$$
\begin{aligned}
y_{n+1}(x)=u_{0}(x)+\sum_{i=1}^{n+1} u_{i}(x) & =Q(x)+\sum_{i=1}^{n+1} \int_{0}^{x} K(x, t) u_{i-1}(t) d t \\
& =Q(x)+\int_{0}^{x}\left[K(x, t) \sum_{i=1}^{n+1} u_{i-1}(t)\right] d t \\
& =Q(x)+\int_{0}^{x}\left[K(x, t) \sum_{i=0}^{n} u_{i}(t)\right] d t \\
& =Q(x)+\int_{0}^{x} K(x, t) y_{n}(t) d t=f y_{n}(x)
\end{aligned}
$$

for any $n \in \mathbb{N}$, then $y_{n+1}=f y_{n}(n \in \mathbb{N})$ is a Picard iteration. By the process of proof of Theorem 2.3, we say that $\left\{y_{n}\right\}$-converges to the fixed point $u(x)$ of $f$. In other words,

$$
u(x)=\lim _{n \rightarrow \infty} y_{n}(x)=\sum_{i=0}^{\infty} u_{i}(x)=\sum_{n=0}^{\infty} u_{n}(x) .
$$

Substituting $u(x)=\sum_{n=0}^{\infty} u_{n}(x)$ into (3.3), we claim that the solution of (3.1) is the following form:

$$
y=\sum_{n=0}^{\infty} \int_{0}^{x}(x-t) u_{n}(t) d t+C_{1} x+C_{0} .
$$

Secondly, we apply our fixed point results to prove the existence and uniqueness of a solution for the following nonlinear integral equation:

$$
x(t)=\int_{a}^{t} k(s, x(s)) d s+h(t)
$$

where $t \in[a, b], a, b \in \mathbb{R}$ with $a<b, h:[a, b] \rightarrow \mathbb{R}$ is a given function, and $k:[a, b] \times \mathbb{R} \rightarrow \mathbb{R}$ is a given continuous mapping. 
Theorem 3.2. Let $\mathrm{L}_{\mathrm{p}}[\mathrm{a}, \mathrm{b}]=\left\{\left.x(\mathrm{t})\left|\int_{\mathrm{a}}^{\mathrm{b}}\right| \mathrm{x}(\mathrm{t})\right|^{\mathrm{p}} \mathrm{dt}<\infty\right\}(0<\mathrm{p}<1)$. Consider (3.5), suppose that the mapping $\mathrm{k}$ satisfies Hölder condition:

$$
|k(s, x(s))-k(s, y(s))|<A|x(s)-y(s)|^{p}
$$

for all $x, y \in L_{p}[a, b]$, where $A>0$ is a constant such that $\frac{A}{2}(2 b-2 a)^{\frac{1}{p}}<1$. Then (3.5) has a unique solution in $\mathrm{L}_{p}[\mathrm{a}, \mathrm{b}]$.

Proof. Let $X=L_{p}[a, b]$. Define a mapping $d: X \times X \rightarrow \mathbb{R}^{+}$by

$$
d(x, y)=\left(\int_{a}^{b}|x(t)-y(t)|^{p} d t\right)^{\frac{1}{p}}
$$

for all $x, y \in X$. Then by Example 1.4, it ensures us that $(X, d)$ is a b-complete b-metric space with coefficient $s=2^{\frac{1}{p}-1}$. Define a mapping $f: X \rightarrow X$ by

$$
f x(t)=\int_{a}^{t} k(s, x(s)) d s+h(t)
$$

for all $t \in[a, b]$. Then the existence of a solution of (3.5) is equivalent to the existence of fixed point of $f$.

Now we prove that $f$ has a unique fixed point in $X$. To this end, combining (3.6), (3.7), and (3.8), we have

$$
\begin{aligned}
d(f x, f y) & =\left(\int_{a}^{b}|f x(t)-f y(t)|^{p} d t\right)^{\frac{1}{p}} \\
& =\left(\int_{a}^{b}\left|\int_{a}^{t} k(s, x(s)) d s-\int_{a}^{t} k(s, y(s)) d s\right|^{p} d t\right)^{\frac{1}{p}} \\
& =\left(\int_{a}^{b}\left|\int_{a}^{t}[k(s, x(s))-k(s, y(s))] d s\right|^{p} d t\right)^{\frac{1}{p}} \\
& \leqslant\left(\int_{a}^{b}\left[\int_{a}^{t}|k(s, x(s))-k(s, y(s))| d s\right]^{p} d t\right)^{\frac{1}{p}} \\
& \leqslant\left(\int_{a}^{b}\left[\int_{a}^{t} A|x(s)-y(s)|^{p} d s\right]^{p} d t\right)^{\frac{1}{p}} \\
& \leqslant\left(\int_{a}^{b} A^{p}\left[\int_{a}^{b}|x(s)-y(s)|^{p} d s\right]^{p} d t\right)^{\frac{1}{p}} \\
& =\left(\int_{a}^{b} A^{p}[d(x, y)]^{p^{2}} d t\right)^{\frac{1}{p}} \\
& =A(b-a)^{\frac{1}{p}}[d(x, y)]^{p} .
\end{aligned}
$$

Accordingly, we have

$$
[s d(f x, f y)]^{p} \leqslant s d(f x, f y) \leqslant A s(b-a)^{\frac{1}{p}}[d(x, y)]^{p} .
$$

Let $\psi(t)=t^{p}(t \geqslant 0)$, then $\psi$ is an altering distance function. Define $F(u, v)=A s(b-a)^{\frac{1}{p}} u(u, v \geqslant 0)$. 
Since $A s(b-a)^{\frac{1}{p}}=\frac{A}{2}(2 b-2 a)^{\frac{1}{p}}<1$, then $F$ is a C-class function. Otherwise, by (3.9), we obtain that

$$
\begin{aligned}
\psi[s d(f x, f y)] & =[s d(f x, f y)]^{p} \\
& \leqslant A s(b-a)^{\frac{1}{p}}[d(x, y)]^{p} \\
& =A s(b-a)^{\frac{1}{p}} \psi(d(x, y)) \\
& \leqslant A s(b-a)^{\frac{1}{p}} \psi\left(M_{i}(x, y)\right) \\
& =F\left(\psi\left(M_{i}(x, y)\right), \varphi\left(M_{i}(x, y)\right)\right)+\beta N(x, y),
\end{aligned}
$$

where $\beta=0, \varphi: \mathbb{R}^{+} \rightarrow \mathbb{R}^{+}$is any altering distance function.

As a consequence, all conditions of Theorem 2.3 are satisfied, then by Theorem $2.3, f$ has a unique fixed point in X. In other words, the integral equation (3.5) has a unique solution in $L_{p}[a, b]$.

Remark 3.3. Regarding differential equation (3.1), Theorem 3.1 gives the argument not only for the existence and uniqueness of a solution, but also for the general mathematical expression of solution. Although the existence and uniqueness of a solution of (3.1) could also be obtained by Peano's theorem, and the space could be deduced if the standard metric is used, whereas, to the best of our knowledge, by utilizing fixed point theory, almost all authors from the existing literature usually merely consider the existence and uniqueness of a solution to differential or integral equation, but they seldom involve the mathematical expression of solution. From this view of point, our results are commendable.

Remark 3.4. In Theorem 3.2, we use Hölder condition (3.6) instead of Lipschitz condition. This is an improvement since Hölder condition is usually weaker than Lipschitz condition. Otherwise, under the conditions of our theorem, we choose $L_{p}[a, b]$ instead of $C([a, b])$ as the range of the solution of (3.5). This is also an improvement because $L_{p}[a, b]$ is a subset of $C([a, b])$.

We finally pose the following problem.

Problem 3.5. How to find the general expression of solution for Theorem 3.2 just like Theorem 3.1 ?

\section{Acknowledgment}

The authors thank the editor and the referees for their valuable comments and suggestions which improved greatly the quality of this paper. The research was partially supported by the National Natural Science Foundation of China (11271045).

\section{References}

[1] A. Aghajani, M. Abbas, J. R. Roshan, Common fixed point of generalized weak contractive mappings in partially ordered b-metric spaces, Math. Slovaca, 64 (2014), 941-960. 1, 1.12, 2.10

[2] H. Alsamir, M. S. M. Noorani, M. Noorani, W. Shatanawi, F. Shaddad, Generalized Berinde-type $(\eta, \xi, \vartheta, \theta)$ contractive mappings in B-metric spaces with an application, J. Math. Anal., 7 (2016), Pages 1-12. 1

[3] A. H. Ansari, Note on " $\varphi-\psi$-contractive type mappings and related fixed point", The 2nd Regional Conference on Mathematics and Applications PNU, (2014), 377-380. 1, 1.8

[4] A. H. Ansari, W. Shatanawi, A. Kurdi, G. Maniu, Best proximity points in complete metric spaces with (P)-property via C-class functions, J. Math. Anal., 7 (2016), 54-67. 1, 1

[5] I. A. Bakhtin, The contraction mapping principle in almost metric space, (Russian) Functional analysis, (Russian), Ulyanovsk. Gos. Ped. Inst., Ulyanovsk, 30 (1989), 26-37. 1, 1.1

[6] M. Boriceanu, M. Bota, A. Petruşel, Multivalued fractals in b-metric spaces, Cent. Eur. J. Math., 8 (2010), 367-377. 1, 1

[7] S. Czerwik, Contraction mappings in b-metric spaces, Acta Math. Inform. Univ. Ostraviensis, 1 (1993), 5-11. 1, 1.1

[8] N. Hussain, V. Parvaneh, J. R. Roshan, Z. Kadelburg, Fixed points of cyclic weakly $(\psi, \varphi, \mathrm{L}, \mathrm{A}, \mathrm{B})$-contractive mappings in ordered b-metric spaces with applications, Fixed Point Theory Appl., 2013 (2013), 18 pages. 1, 1.7

[9] M. Jovanović, Z. Kadelburg, S. Radenović, Common fixed point results in metric-type spaces, Fixed Point Theory Appl., 2010 (2010), 15 pages. 1, 2.2 
[10] M. S. Khan, M. Swaleh, S. Sessa, Fixed point theorems by altering distances between the points, Bull. Aust. Math. Soc., 30 (1984), 1-9. 1, 1, 1.10

[11] P. Kumam, W. Sintunavarat, The existence of fixed point theorems for partial q-set-valued quasi-contractions in b-metric spaces and related results, Fixed Point Theory Appl., 2014 (2014), 20 pages. 1, 1, 2.2

[12] R. Miculescu, A. Mihail, A generalization of Matkowski's fixed point theorem and Istrăţescu's fixed point theorem concerning convex contractions, J. Fixed Point Theory Appl., 184 (2015), 1-9.

[13] V. Ozturk, A. H. Ansari, Common fixed point theorems for mappings satisfying (E.A)-property via C-class functions in b-metric spaces, Appl. Gen. Topol., 18 (2017), 45-52. 1, 1

[14] V. Ozturk, S. Radenović, Some remarks on b-(E.A)-property in b-metric spaces, SpringerPlus, 5 (2016), 10 pages. 1.2

[15] J. R. Roshan, V. Parvaneh, S. Sedghi, N. Shobkolaei, W. Shatanawi, Common fixed points of almost generalized $(\psi, \varphi)_{s^{-}}$ contractive mappings in ordered b-metric spaces, Fixed Point Theory Appl., 2013 (2013), 23 pages. 1, 2.10

[16] W. Shatanawi, Fixed and common fixed point for mappings satisfying some nonlinear contractions in b-metric spaces, J. Math. Anal., 7 (2016), 1-12.

[17] W. Shatanawi, A. Pitea, R. Lazović, Contraction conditions using comparison functions on b-metric spaces, Fixed Point Theory Appl., 2014 (2014), 11 pages. 1

[18] W. Shatanawi, M. Postolache, A. H. Ansari, W. Kassab, Common fixed points of dominating and weak annihilators in ordered metric spaces via C-class functions, J. Math. Anal., 8 (2017), 54-68. 1

[19] S. L. Singh, S. Czerwik, K. Król, A. Singh, Coincidences and fixed points of hybrid contractions, Stability of functional equations and applications, Tamsui Oxf. J. Math. Sci., 24 (2008), 401-416. 1, 2.2

[20] W. Sintunavarat, Fixed point results in b-metric spaces approach to the existence of a solution for nonlinear integral equations, Rev. R. Acad. Cienc. Exactas Fs. Nat. Ser. A Math. RACSAM, 110 (2016), 585-600. 1, 1.2, 1, 1.5, 1.6, 1.11, $1,2.10$

[21] W. Sintunavarat, Nonlinear integral equations with new admissibility types in b-metric spaces, J. Fixed Point Theory Appl., 18 (2016), 397-416. 1.2, 1.6, 1.11

[22] O. Yamaod, W. Sintunavarat, Y. J. Cho, Common fixed point theorems for generalized cyclic contraction pairs in b-metric spaces with applications, Fixed Point Theory Appl., 2015 (2015), 18 pages.

[23] O. Yamaod, W. Sintunavarat, Y. J. Cho, Existence of a common solution for a system of nonlinear integral equations via fixed point methods in b-metric spaces, Open Math., 14 (2016), 128-145. 1, 1, 1, 2.10 